\title{
PENATALAKSANAAN FISIOTERAPI MENGGUNAKAN FOOT CORE STRENGTHENING EXERCISE UNTUK MENINGKATKAN AKTIFITAS FUNGSIONAL PADA KASUS PLANTAR FACITIS
}

\author{
Wanti Hasmar, Faridah \\ Program Studi DIII Fisioterapi \\ STIKes Baiturrahim Jambi \\ Email: \\ Wanti.cemar@gmail.com
}

\begin{abstract}
ABSTRAK
Latar Belakang : Plantar Fascitis adalah peradangan pada plantar fascia Penguluran plantar fascia yang berlebihan dapat mengakibatkan kerobekan kemudian menimbulkan suatu iritasi pada plantar fascia, kelemahan dari otot-otot intrinsik kaki, penambahan berat badan atau aktivitas yang berat, hal tersebut mengakibatkan tarikan pada plantar fascia, sehingga terjadi kerobekan dan timbul iritasi pada plantar fascia. Pasien plantar fascitis mengalami gangguan akitifitas fungsional sehingga pasien harus diberikan penangana yang tepat, salah satunya menggunakan foot core strengthening. Penelitian ini bertujuan untuk mengetahui penatalaksanaan foot core strengthening dalam meningkatkan aktifitas fungsional pada kasus plantar fasciitis. Metode yang digunakan adalah metode studi kasus dengan 1 orang responden menggunakan alat ukur skala Jette untuk mengukur aktifitas fungsional. Hasil dari penelitian yang dilakukan di Kecamatan kota baru, kota jambi ini adalah foot core strengthening selama selama 12 kali terapi dalam 4 minggu dapat meningkatkan aktifitas fungsional pasien plantar fasciitis. Kesimpulan penelitian ini adalah foot core streghtening dapat meningkatkan aktifitas fungsional pasien plantar fasciitis karena latihan ini dapat meningkatan kekuatan otot dan ketahanan otot intrinsik pada kaki, ketika otot intrinsik sudah kuat plantar fascia tidak bekerja dengan berat sehingga terjadi penurunan peradangan pada plantar fascia sehingga dapat meningkatkan aktifitas fungsional.
\end{abstract}

Kata kunci : Plantar fasciitis, foot core strengthening, skala jette.

ABSTRACT

Background : Plantar Fascitis is inflammation of the plantar fascia Excessive stretching of the plantar fascia can result in a tear and then cause irritation to the plantar fascia, weakness of the intrinsic muscles of the foot, weight gain or strenuous activity, it causes a pull on the plantar fascia, This results in tearing and irritation of the plantar fascia. Plantar fasciitis patients have functional activity disorders so the patient must be given proper management, one of which is using foot core strengthening. This study aims to determine the management of foot core strengthening in increasing functional activity in plantar fasciitis cases. The method used is a case study method with 1 respondent using a Jette scale measuring instrument to measure functional activity. The results of a study conducted in Kota Baru Subdistrict, Jambi City, showed that foot core strengthening for 12 times of therapy in 4 weeks could improve the functional activity of plantar fasciitis patients. The conclusion of this study is that foot core stretching can increase the functional activity of plantar fasciitis patients because this exercise can increase muscle strength and intrinsic muscle endurance in the feet, when the intrinsic muscles are strong the plantar fascia does not work hard so that there is a decrease in inflammation in the plantar fascia so that it can increase activity. functional.

Keywords: Plantar fasciitis, foot core strengthening, jette scale. 


\section{PENDAHULUAN}

Sehat menurut WHO adalah suatu keadaan sempurna secara fisik mental, kesejahteraan social, dan bukan sekedar tidak adanya sakit atau kelemahan (WHO,2013). Kesehatan adalah keaadaan sehat baik secara fisik, mental, spiritual maupun sosial yang memungkinkan setiap orang untuk

hidup produktif dan ekonomis. Upaya kesehatan adalah stiap kegiatan atau serangkaian kegiatan yang dilakukan secara terpadu, terintegrasi dan berkesinambungan untuk memelihara dan meningkatkan derajat masyarakat dalam bentuk pencegahan penyakit, peningkatan kesehatan, pengobatan penyakit pemulihan kesehatan oleh masyarakat maupun pemerintah (UU.No. 36 Tahun 2009).

Sebuah penelitian yang dilakukan oleh Suzan, ditemukan bahwa plantar fasciitis menyumbang 41,5\% masalah pada kasus musculoskeletal disetiap pusat perawatan tersier di California, Amerika Serikat. Sekitar 10\% dari populasi warga Amerika Serikat mengeluh karena nyeri pada kasus plantar fascitis dan menghasilkan satu juta kunjungan profesional untuk pengobatan plantar fascitis setiap tahunnya. Di sisi lain, menyumbang lebih dari 600.000 pasien rawat jalan setiap tahunnya di Amerika Serikat (Goweda, 2015).

Menurut data yang diperoleh dari laporan bulanan poli rehab medic Rumah Sakit Tentara Bhakti Wira Tamtama Semarang Jawa Tengah pada tahun 2017 angka pasien yang mengalami fasciitis plantaris pada bulan januari sampai bulan desember terdapat 67 pasien yang mengalami kasus Plantar Fascitis tersebut. dilakukan untuk menambah nilai kekuatan otot yang lemah yang terkadang diakibatkan karna nyeri (Kuswardani, 2018).

Plantar Fascitis adalah suatu peradangan pada plantar fascia. Pita tebal fascia ini terletak di permukaan plantar kaki, terletak pada calcaneus dan sebagai penunjang ke arah jari-jari kaki. Penguluran plantar fascia yang berlebihan dapat mengakibatkan kerobekan kemudian menimbulkan suatu iritasi pada fascia plantaris, tepatnya mengenai bagian anteromedial tuberositas calcaneus yang terkadang dapat juga terjadi pada bagian posterior calcaneus (Kuswardani, 2018).

Peradangan adalah respon tubuh terhadap cedera jaringan yang terjadi akibat tekanan, gesekan, beban berulang dan trauma eksternal. Trauma dikaitkan dengan perdarahan yang menyebabkan pembengkakan dan peningkatan tekanan. Selain itu peradangan juga mengakibatkan kekakuan pada otot gastrocnemius dan soleus membatasi gerakan fleksi pada ankle dan menimbulkan pronasi subtalar yang berlebihan. Akibatnya adalah terjadi stres dan penekanan pada plantar fascia. Kelemahan dari otototot intrinsik kaki dan yang utama yaitu otot tibialis posterior pada tumit, penambahan berat badan atau aktivitas yang berat, kekurangan propriosepsi.

Hal tersebut akan mengakibatkan tarikan pada plantar fascia, sehingga terjadi kerobekan dan timbul iritasi pada plantar fascia. Kurangnya fleksibilitas plantar fascia menyebabkan daya regang plantar fascia menurun dan akibatnya plantar fascia mudah mengalami cedera. Aktifitas seperti berdiri atau berjalan yang lebih lama dibanding biasanya akan menimbulkan overstretch pada struktur plantar fascia. Deformitas seperti pes cavus atau pes planus menimbulkan perubahan alignment dari calcaneus sehingga mempengaruhi arcus plantaris dalam aktifitasnya menumpu berat badan saat berdiri atau berjalan. Penggunaan alas kaki yang keras menimbulkan penekanan pada plantar fascia. Berat badan yang berlebihan akan memberikan beban yang besar pada kaki terutama daerah tumit yang menerima persentase tekanan yang besar sehingga origo struktur plantar fascia mengalami penekanan (Kuswardani, 2018).

Menurut Schwartz Plantar Fascitis adalah strain umum yang menyebabkan cedera berlebihan yang terjadi karena traksi berulang pada daerah plantar fascia di bawah calcaneus distal. Cedera kaki berlebihan ini $80 \%$ karena nyeri plantar dan 8-10\% adalah cedera karena berlari. Hal ini juga sering terjadi pada orang-orang yang kurang duduk dan atlet, serta dianggap akibat fatal dari gaya hidup ataupun olahraga berat. Literatur saat ini menunjukkan bahwa Plantar 
Fascitis lebih tepat disebut fasciosis karena kronisitas penyakit dan bukti degenerasi daripada pembengkakan.

Pengobatannya seringkali mengalami kesulitan karena mekanisme yang kurang dipahami, berkaitan dengan tubuh yang dapat menyembuhkan degenerasi kronis daripada dengan peradangan akut. Tetapi pada keadaan akut dapat mengakibatkan gangguan pada kaki, lutut, pinggul dan punggung (Kuswardani, 2018).

Foot core strengthening adalah penguatan otot-otot intrinsik pada kaki berfungsi untuk melatih meningkatkan kekuatan otot-otot intrinsic kaki dapat memberikan manfaat dengan meningkatkan gerakan melengkung dan memanjang medial telapak kaki dan kemampuan untuk mengatasi perubahan kontrol kaki yang dinamis. Mempraktikkan berbagai teknik penguatan dalam rehabilitasi atau pelatihan dapat memberikan strategi yang sangat baik untuk mengurangi kejadian atau mencegah efek dari cedera berlebihan pada ekstremitas bawah yang terkait dengan control kaki yang buruk (Francois, 2016).

Mekanisme Foot core strengthening bertujuan untuk mengembalikan koordinasi otot instrinsik kaki, dengan menggunakan otot intrinsik untuk menarik sendi metatarsophalangeal pertama ke arah kalkaneus saat lengkung longitudinal medial diangkat. Saat lengkungan naik selama latihan ini, itu juga disebut sebagai (foot doming) ketika memfleksikan phalang seperti mencengkramkan kaki otot instrinsik pada kaki disana akan aktif maka akan terjadi peningkatan kekuatan otot dan

ketahan otot intrinsik pada kaki, ketika otot intrinsik sudah kuat plantar fascia tidak bekerja dengan berat sehingga terjadi penurunan peradangan pada plantar fascia (Patrick, 2016).

Menurut penelitian Patrick (2015) The Foot Core System A New Paradigm For Understanding Instrinsic Foot Muscle Function. bahwa, dengan dilakukan latihan Foot core strengthening dilakukan selama 4 minggu. Pasien mengontraksikan otot intrinsiknya, pada pasien pes cavus dan pes planus yang membuat penderita mengalami plantar fasciitis menunjukkan hasil yang signifikan dapat meningkatkan kekuatan otot dan fleksi pada kaki dan meningkatkan aktivitas fungsional penderita plantar fascitis.

\section{METODE PENELITIAN}

Jenis penelitian yang dilakukan merupakan studi kasus (case study) dengan 1 orang responden yang merupakan pasien plantar fascitis. Penelitian ini dilaksanakan di Kota Jambi, Kecamatan jelutung , provinsi jambi selama 4 minggu dimulai pada minggu ke-1 sampai ke -4 bulan januari tahun 2020. Data penelitian yang diperoleh terdiri dari 2 yaitu data primer dan data sekunder. Data primer diperoleh dari pemeriksaan langsung kepada pasien dan data sekunder dengan melihat status medical record dan pemeriksaan lain yang mendukung seperti pemeriksaan hasil laboratorium.

Instrumen penelitian yang digunakan yaitu:

1. Alat tulis digunakan dengan tujuan sebagai alat pendukung dalam penelitian.

2. Skala Jette merupakan tes yang dapat menentukan tingkat keseimbangan.

3. handuk kasar digunakan sebagai alas penunjang saat latihan.

Tahapan pelaksanaan penelitian sebagai berikut:

1. Pada kunjungan awal, peneliti melakukan anamnesis dan pemeriksaan fisik kepada pasien seperti pemeriksaan spesifik

2. Pada saat ini juga dilakukan pre test aktifitas fungsional menggunakan Skala Jette sebagai data awal. Pengukuran dilakukan dengan melakukan 3 item pengujian aktifitas fungsional. Kriteria dari pengukuran ini ada 4 yaitu berat $(>40)$, sedang (25-40), ringan $(18-24)$ dan normal $(<18)$. 
3. Setelah pemeriksaan dilakukan dan telah dipastikan bahwa kondisi pasien aman untuk melakukan latihan maka peneliti memulai penatalaksanaan foot core strengthening dengan menggunakan handuk kasar yang dilettakan di atas telapak kaki.

4. Setelah itu, penatalaksanaan foot core strengthening Pasien di instruksikan untuk mengkontraksikan otot intrinsik pada kaki seperti mencengkram kaki sehingga telapak kaki melengkung atau membentuk arcus lakukan dan ditahan 6 detik dan dulangi dengan 8 kali pengulangan selama 4 minggu.

5. Peneliti datang ke rumah pasien $3 x$ seminggu selama 4 minggu berturut-turut dengan 8 kali pengulangan.

6. Evaluasi aktifitas fungsional menggunakan skala jette dilakukan hari terakhir di setiap minggunya.

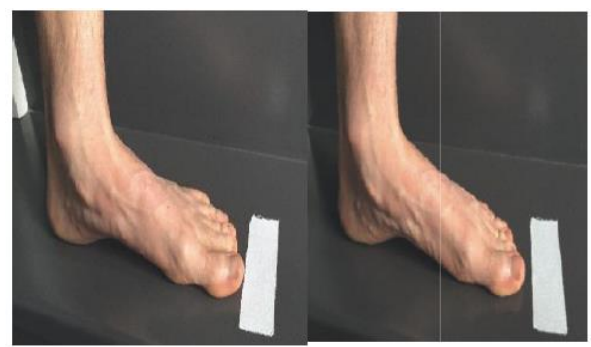

Gambar 1. Foot core strengthening

(Sumber : Francois dkk, 2015).

\section{HASIL DAN PEMBAHASAN}

Berdasarkan pemeriksaan spesifik kepada pasien plantar fasciitis, diperoleh hasil antara lain: karakteristik pasien adalah pasien wanita berusia 40 tahun dengan status karyawan swasta. Hasil pemeriksaan spesifik dengan Windlass Test positif. Hasil pemeriksaan terdapatnya problematika berupa gangguan aktifitas fungsional saat diam dan juga saat beraktivitas. Dari problematik yang didapatkan tersebut, peneliti memberikan penatalaksanaan untuk meningkatkan aktifitas fungsional dengan foot core strengthening. Hasil pengukuran aktifitas fungsional pasien diukur dan dievaluasi setiap minggunya seperti yang tercantum dalam tabel berikut.

Tabel 1. Hasil Evaluasi Skala Jette

\begin{tabular}{lll}
\hline Minggu & Total Skor & Interpretasi \\
\hline Minggu ke-1 & 35 & Sedang \\
\hline Minggu ke-2 & 33 & Sedang \\
\hline Minggku ke-3 & 30 & Sedang \\
\hline Minggu ke-4 & 25 & Ringan \\
\hline
\end{tabular}

Dari penelitian yang telah dilakukan ditemukan bahwa pada pasien tersebut terjadi peningkatan aktifitas fungsional dengan intervensi foot core strengthening selam 4 minggu dengan 8 kali pengulangan. Foot core strengthening adalah penguatan otot-otot intrinsik pada kaki berfungsi untuk melatih meningkatkan kekuatan otot-otot intrinsic kaki dapat memberikan manfaat dengan meningkatkan gerakan melengkung dan memanjang medial telapak kaki dan kemampuan untuk mengatasi perubahan kontrol kaki yang dinamis (Francois, 2016).

Menurut penelitian Patrick (2016) The Foot Core System A New Paradigm For Understanding Intrinsic Foot Muscle Function bahwa, dengan dilakukan latihan Foot core strengthening dilakukan selama 4 minggu. Pasien mengontraksikan otot intrinsiknya, pada pasien pes cavus dan pes planus yang membuat penderita mengalami plantar fasciitis menunjukkan hasil yang signifikan dapat meningkatkan kekuatan otot dan fleksi pada kaki dan meningkatkan aktivitas fungsional penderita plantar fasciitis. 


\section{KESIMPULAN}

Hasil evaluasi dari penatalaksanaan fisioterapi yang dilakukan yaitu adanya peningkatan aktifitas fungsional pada pasien plantar fasciitis dengan intervensi foot core strengthening yang diukur dengan skala jette dengan skor 35, kategori sedang sebelum terapi menjadi skor 25 (ringan). Saran untuk penelitian selanjutnya agar dapat menggunakan metode penelitian lain dengan menggunakan lebih banyak sampel penelitian.

\section{PENGHARGAAN}

Penulis menyampaikan ucapan terima kasih sedalam-dalamnya kepada semua pihak yang telah memberikan dukungan semangat, bantuan berupa bimbingan, arahan, motivasi, dan doa selama proses penelitian dan penulisan laporan penelitian. Penulis dengan penuh hormat dan tulus dari hati yang paling dalam menyampaikan rasa terimakasih sebesar-besarnya kepada rekan peneliti dan civitas akademika STIKes Baiturrahim Jambi yang telah membantu dalam penelitian ini.

\section{DAFTAR PUSTAKA}

Kuswardani., Suci amanati dan Novian. 2018, Pengaruh Infra Red, Ultrasound dan terapi latiham pada fasciitis plantaris. Jurnal Fisioterapi dan Rehabilitasi (JFR) Vol. 2 No.1, Tahun 2018, ISSN 254-8716. Diakses pada : Tanggal 25 Februari 2020 Dari : jurnal.akfis-whs.ac.id

Fourchet, Francois dan Boris Gojanovic. 2015. Foot core strengthening an Update About the Intrinsic Foot Muscles Recruitment.Switzerland. British Journal Of Sport Medicine. Diakses pada tanggal : 06 Desember 2020. Dari: https://www.researchgate.net > 2610. The foot core system: A new paradigm for understanding intrinsic foot muscle. DOI: 10.1136/bjsports2015-095573.15

Jamed dan Robert, Diagnosis dan treatment of plantar fasciitis. American Family Physican, 2011, Diakses pada tanggal 25 juli 2020. Dari :https://www.aafp.org/afp/2011/0915/p676.html

Mc Keon, Patrick O da., dan Dennis M. Bramble 2016 The Foot Core System A New Paradigm For Understanding Intrinsic Foot Muscle Function British Journal Of Sport Medicine. Diakses pada : tanggal 25 februari 2020. Dari : https://www.researchgate.net/publication/261035124 DOI:10.1136/bjsports-2013-092690.

Muawanah, Siti dan lit Selviani 2018 Penambahan Neuromuscular Tapping Lebih Baik Dari Pada Ultrasoud Saja Untuk Menurunkan Nyeri Pada Kasus Plantar Fascitis. Jurnal IImiah Fisioterapi (JIF) Volume 1 nomor 02. Diakses pada : tanggal 25 februari 2020. Dari :https://www.google.com/url?sa=t\&source=web\&rct=j\&url=http://jurnal.univrab.ac.id.

Ozdemir, Calisanneler, S dan A. 2007 Tarsal Tunnel Syndrome in a Patient onLong-Tern Pritoneal Dialysis. Turkish Neurosurgery, Vol: 17, No. 4,283-285. Diakses pada tanggal : 27 Februari 2020. Dari :turkishneurosurgery.org.tr > ...PDF Tarsal Tunnel Syndrome in a Patienton Long-Term ... - Turkish Neurosurgery. 